\title{
Public Opinion Regarding The New National Children's Obligatory Vaccination Schedule (2018)
}

\author{
${ }^{1}$ Lamiaa L. El-Hawy, ${ }^{2}$ Hanaa S. Said \\ ${ }^{1}$ Department of community, environmental and occupational medicine, ${ }^{2}$ Department of \\ Family Medicine, Faculty of Medicine, Zagazig University, Egypt.
}

\begin{abstract}
Background: Childhood vaccination has a great role in major worldwide reductions in morbidity and mortality and is considered to be one of the most effective public health interventions in terms of numbers of infections and deaths avoided per year. Objectives: To assess knowledge and practice regarding the new children's obligatory vaccination schedule (2018) and to identify barriers of incomplete vaccination and the sources of their information. Method: A cross-sectional study was conducted on 290 mothers. Through a multistage sampling technique, four health facilities were selected to represent Sharkia governorate whereas the sample units were proportionally allocated. The study included mothers of children younger than one year of age. Mothers were interviewed using the Fahmy questionnaire to assess the socioeconomic status and a modified semi-structured questionnaire to assess mothers' knowledge and practice and to identify sources of their information and possible barriers of incomplete vaccinations. Results: The studied mothers showed an inadequate total knowledge score (61\%) and poor total practice (59\%). Mothers' age, education, and occupation affected the total knowledge. Mothers' education, occupation, and social class were the determinants affecting the total practice score. Health care providers $(71 \%)$ and family relatives $(67 \%)$ were the commonest sources of information. Sick baby $(63 \%)$ and presence of family problems $(31 \%)$ were the commonest barriers for none or incomplete immunization. Conclusion: The knowledge and practice of the studied mothers were unsatisfactory. Continuous health education should be provided to overcome the found barriers and encourage complete immunization.
\end{abstract}

Keywords: awareness, barriers, practice, children, immunization.

Corresponding author: Hanaa Salah Said Elsayed Email address: drhanasalah@yahoo.com

\section{Introduction}

Children's compulsory vaccinations have greatly decreased the burden of many infectious diseases. It also prevents illness, disability, and death from vaccinepreventable diseases like Measles, Pertussis, Diphtheria, Polio, Rubella, and Tetanus. ${ }^{1,2}$

Immunizing a child is greatly reducing the costs of disease treatment, providing a healthy childhood and also reducing poverty and suffering. ${ }^{3}$ World Health
Organization reported that about (115 million) infants received DiphtheriaTetanus and Pertussis vaccine worldwide and about $85 \%$ of the world's children had received one dose of measles and polio vaccine per year and this lead to prevention of about (2 to 3 million) deaths each year from Diphtheria, Tetanus, Pertussis (whooping cough), and Measles. ${ }^{4}$ The Egyptian ministry of health and population modified children's obligatory 
vaccination schedule in 2018 by adding new vaccines like the Salk vaccine for polio and Haemophilus influenza type B vaccine and giving a birth dose of hepatitis $B$ vaccine. The coverage rates of compulsory vaccination were ranged from (96-98\%) in 2010 but these rates became ranged from (94-96\%) in 2018, and in the same report, the coverage rate of newly added hepatitis $B$ vaccine birth dose was only $(89 \%){ }^{5}$

Mothers' knowledge and practice play an important role in accomplishing complete immunization before the first birthday of the child. Many factors participate in the success or failure of immunization program. ${ }^{6}$ For example, unawareness of side effects and contraindications of immunization, negative perceptions about immunization in mild illness, and mother's fear of vaccination. All of the previous factors were considered as the major barriers to childhood vaccination. ${ }^{7}$ In many countries, the number of parents who were refusing consent for their children vaccination have been increased. ${ }^{8}$

Good knowledge and practices of mothers help to complete vaccination of their children and to decrease the burden of dreadful infectious diseases, which are best prevented and controlled by vaccination. ${ }^{6}$

This work aimed to assess knowledge and practice about the updated children's obligatory vaccination among mothers attending health units in Sharkia governorate and to identify barriers for incomplete immunization and the sources of their information.

\section{Method}

A cross-sectional study was conducted on (290) mothers based on the prevalence of poor practice about children obligatory vaccination among mothers was $25.2 \%$ and the total population (number of children aged less than one year in Sharkia governorate) was 206,388 according to the Central Agency for Public Mobilization and Statistics (CAPMAS, 2017), using an online open epi program at $95 \%$ confidence level and 5\% precision.

Through a multistage sampling technique, Zagazig and Belbeis health districts were selected by simple random technique to represent the Sharkia governorate (which consisted of 19 health districts).

Belbeis health district includes one urban health center and (33) rural health units. Two health facilities were selected randomly to represent urban and rural areas of the district. In the same way, two health facilities were selected to represent urban and rural areas of the Zagazig health district (which includes only one urban health center and (31) rural health units). So, four health facilities were selected to represent the Sharkia governorate. Sample units were collected by systematic random sampling from each health facility, the sample distributed by the proportional allocation method on the selected health facilities.

The study included mothers of children younger than one year of age attending the selected health facilities for obligatory vaccination according to the national vaccination schedule. Mothers were interviewed using the scoring system of Fahmy et al., $2015^{10}$ to assess the sociodemographic characteristics, and a selfdesigned questionnaire with the help of a previous study done in Egypt ${ }^{9}$ to assess the knowledge (importance of the vaccines, routes of vaccines administration, contraindications of vaccinations) and practice (dealing with vaccination's fever, managing the swelling of vaccination site) of the selected mothers. Extra questions regarding the updated national vaccination schedule 
2018 (do you know the newly added vaccines, what is the importance of the newly added vaccines, targeting what

Table (1): Socio-demographic data of the studied group

\begin{tabular}{|c|c|c|}
\hline \multirow{2}{*}{$\begin{array}{l}\text { Socio-demographic } \\
\text { data }\end{array}$} & \multicolumn{2}{|c|}{$\begin{array}{c}\text { Study group } \\
(\mathrm{n}=290)\end{array}$} \\
\hline & No & $\%$ \\
\hline \multicolumn{3}{|l|}{ Age/ years } \\
\hline Mean + SD & $28.5 \pm 5.6$ & \\
\hline Range & $19-38$ & \\
\hline - $\leq 30$ years & 189 & 65.1 \\
\hline - > 30 years & 101 & 34.8 \\
\hline \multicolumn{3}{|l|}{$\begin{array}{l}\text { Number of family } \\
\text { members }\end{array}$} \\
\hline$\bullet \leq 4$ & 129 & 44.5 \\
\hline - $>4$ & 161 & 55.5 \\
\hline \multicolumn{3}{|l|}{ Residence } \\
\hline - Rural & 153 & 52.8 \\
\hline - urban & 137 & 47.2 \\
\hline \multicolumn{3}{|l|}{ Education } \\
\hline \multicolumn{3}{|l|}{ - Less than Secondary } \\
\hline - Secondary & 57 & 19.7 \\
\hline \&Intermediate & 146 & 50.3 \\
\hline - Higher education & 87 & 30.0 \\
\hline \multicolumn{3}{|l|}{ Occupation } \\
\hline - Non-working & 182 & 62.8 \\
\hline - Working & 108 & 37.2 \\
\hline \multicolumn{3}{|l|}{ SES } \\
\hline - Low & 69 & 23.8 \\
\hline - Middle & 179 & 61.7 \\
\hline - High & 42 & 14.5 \\
\hline
\end{tabular}

diseases) and possible barriers for incomplete vaccination were added. The questionnaire was validated by panels of experts in community and family medicine departments. A pilot (10\% of the total sample) was implemented to estimate the time needed to obtain the required information, and there were no administrative or technical obstacles found (the total sample included the pilot sample (internal pilot sample)). The questionnaires took about 15 minutes to be fulfilled. The study implemented at a period of 8 months (from July 2019 to January 2020).

Social class was classified according to Fahmy and his colleagues into high (33.6$48)$, middle $(19.2-<33.6)$, and low $(<19.2)$ depending on the score calculated (48). Regarding knowledge and practice items the correct answer scored= (1) and the Incorrect answer scored $=(0)$. Adequacy of knowledge and practice was as follows: cut off point is $60 \%$ whereas $>60$ was considered as adequate knowledge and good practice and $\leq 60 \%$ was considered as inadequate knowledge and poor practice 11.

Administrative approval: The study was approved by the Sharkia health directorate. An official permission letter was obtained from the authority and directed to the selected health districts and health facilities.

\section{Ethical approval}

Ethical considerations were taken through the whole study including fully informed participants with the purpose and nature of the study and then oral consent was taken from participants. Coded numbers for each participant were used to guarantee privacy. Official approval from the Institutional review board (IRB) was taken (ZU-IRB \#5059).

\section{Statistical analysis}

Data were analyzed using the Statistical Package of Social Science (SPSS) program for Windows (Standard version 20). The normality of data was first tested with a one-sample Kolmogorov-Smirnov test. Quantitative data were described using mean \pm SD (standard deviation).Qualitative data were described using the number and percent. Association between categorical variables was tested using the Chi-square test and Chi-square for trend. Logistic regression was used to identify independantant predictors for 
adequate knowledge and good ptactice about childen obligatory vaccination. Epi used to calculate crud odds ratio and Info version 7 statistical packages was Confidence interval

Table (2): Relation between Socio-demographic data and total knowledge score about children obligatory vaccination among the studied sample

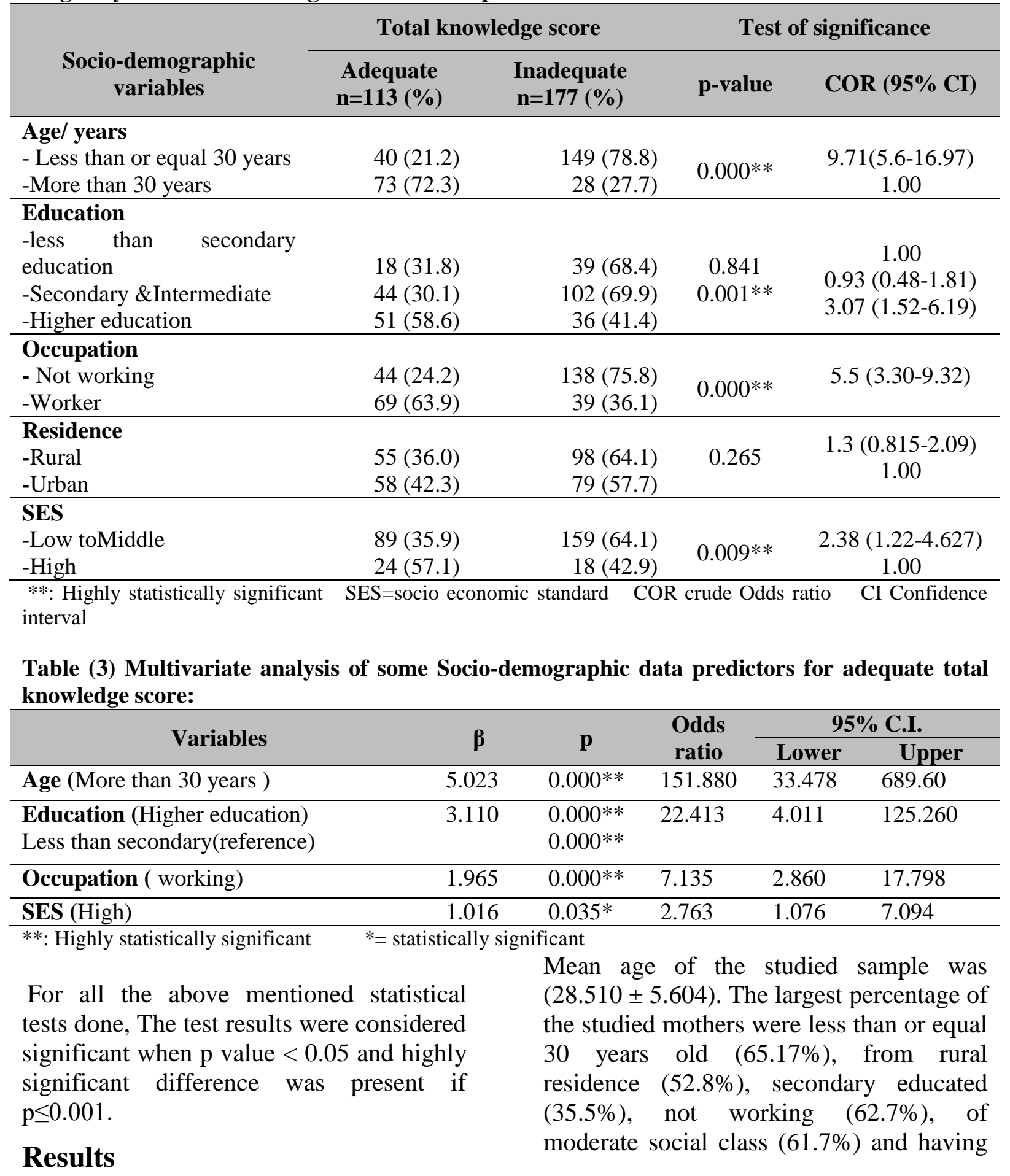


more than four family members $(55.5 \%)$ (Table1).
The majority of the studied sample were having inadequate total knowledge score $(177 / 290)(61.0 \%)$ and poor total behavior

Table (4): Relation between Socio-demographic data and total practice score about children obligatory vaccination among the studied sample

\begin{tabular}{|c|c|c|c|}
\hline \multirow[b]{2}{*}{ Socio-demographic variables } & Total practice score & \multicolumn{2}{|c|}{ Test of significance } \\
\hline & $\begin{array}{c}\text { Poor } \\
\mathrm{n}=171(\%)\end{array}$ & p-value & $\operatorname{COR}(95 \% \mathrm{CI})$ \\
\hline $\begin{array}{l}\text { Age/ years } \\
-\leq 30 \text { years } \\
->30 \text { years }\end{array}$ & $\begin{array}{r}117(61.9) \\
54(53.5)\end{array}$ & 0.164 & $\begin{array}{l}1.4(0.86-2.30) \\
1.00\end{array}$ \\
\hline $\begin{array}{l}\text { Education } \\
\text {-less than secondary education } \\
\text {-Secondary \&Intermediate } \\
\text {-Higher education }\end{array}$ & $\begin{array}{l}39(68.4) \\
93(63.7) \\
39(44.8)\end{array}$ & $\begin{array}{c}0.526 \\
0.005^{*}\end{array}$ & $\begin{array}{c}1.00 \\
1.2(0.64-2.37) \\
2.67(1.32-5.37)\end{array}$ \\
\hline $\begin{array}{l}\text { Occupation } \\
\text { - Not working } \\
\text {-Worker }\end{array}$ & $\begin{array}{r}119(65.4) \\
52(48.1)\end{array}$ & $0.004 * *$ & $\begin{array}{c}2.03(1.25-3.31) \\
1.00\end{array}$ \\
\hline $\begin{array}{l}\text { Residence } \\
\text {-Rural } \\
\text {-Urban }\end{array}$ & $\begin{array}{l}87(56.9) \\
84(61.3)\end{array}$ & 0.442 & $\begin{array}{c}0.83(0.52-1.33) \\
1.00\end{array}$ \\
\hline $\begin{array}{l}\text { SES } \\
\text {-Low to Middle } \\
\text {-High }\end{array}$ & $\begin{array}{r}159(64.1) \\
12(28.6)\end{array}$ & $0.000 * *$ & $\begin{array}{c}4.47(2.18-9.16) \\
1.00\end{array}$ \\
\hline $\begin{array}{l}\text { *: statistically significant **: Highly statistically s } \\
\text { Odds ratio CI Confidence interval } \\
\text { Table (5) Multivariate analysis of some Socio } \\
\text { practice score: }\end{array}$ & mographic dat: & predic & $\begin{array}{l}\text { tandard, COR crude } \\
\text { s for good total }\end{array}$ \\
\hline Variables & $\begin{array}{l}\text { Od } \\
\text { rat }\end{array}$ & & $\begin{array}{ll}\text { 95\% C.I. } \\
\text { ver } \quad \text { Upper }\end{array}$ \\
\hline $\begin{array}{l}\text { Education(Higher education) } \\
\text { less than secondary education(reference) }\end{array}$ & $\begin{array}{l}0.129 \\
0.315\end{array}$ & 0.0 & 4.317 \\
\hline Occupation( working) & 0.096 & & 2.922 \\
\hline SES (High) & $0.000 * *$ & & 9.313 \\
\hline $\begin{array}{l}\text { **: } \\
\text { score }(171 / 290)(59.0 \%) \text { about children } \\
\text { obligatory vaccination (results not } \\
\text { tabulated) } \\
\text { There was a statistically significant } \\
\text { relationship between age, education, } \\
\text { occupation and social class with total } \\
\text { knowledge score about children obligatory } \\
\text { vaccination (p<0.05) (Table 2). } \\
\text { where mothers with age more than } 30 \\
\text { years, highly educated, working and of high }\end{array}$ & $\begin{array}{l}\text { statistically } \\
\text { social calss } \\
\text { knowledge }(9,3, \\
\text { more than motl } \\
\text { equal } 30 \text { yec } \\
\text { education, not w } \\
\text { social class (Tab } \\
\text { Mothers, their } \\
\text { highly educated, } \\
\text { class were signi } \\
\text { for adequate kno } \\
\text { obligatory va }\end{array}$ & $\begin{array}{l}\text { were } \\
5 \text { and } 2 \mathrm{t} \\
\text { ers with } \\
\text { rs, less } \\
\text { orking, an } \\
\text { le 2). } \\
\text { ages Mo } \\
\text { working, } \\
\text { icant ind } \\
\text { wledge sc } \\
\text { ccination }\end{array}$ & $\begin{array}{l}\text { aving adequate } \\
\text { mes) respectively } \\
\text { age less than or } \\
\text { than secondary } \\
\text { of low to middle } \\
\text { and of high social } \\
\text { pendent variables } \\
\text { ore about children } \\
\text { (AOR=151.88, }\end{array}$ \\
\hline
\end{tabular}


22.41, 7.14 and 2.76) folds respectively (Table 3).

There was a statistically significant relationship between education, occupation and social class with total practice score about children obligatory vaccination $(\mathrm{p}=0.005, \quad \mathrm{p}=0.004$ and $\mathrm{p}=0.000)$ respectively (Table 4).

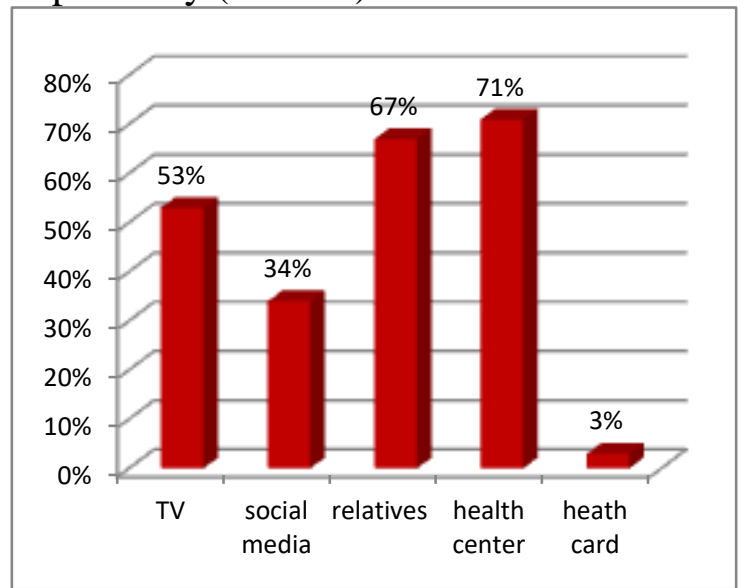

*: mothers were allowed to choose more than one choice

Figure (1) shows sources of mothers' information about children obligatory vaccination

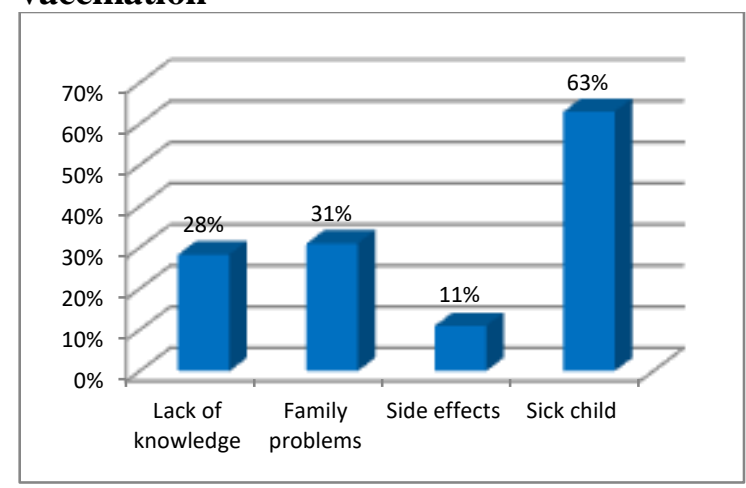

*:the total percent of the columns above $100 \%$ as more than one answer was allowed

Figure (2) shows barriers of none or incomplete vaccination among the studied sample

where highly educated mothers, working and of high social calss were having good practice (2, 2 and 4 times) respectively more than mothers their education less than secondary educated, not working mothers and of low to middle social class (Table 4).
Mothrs of high social class was significant independent variable for good practice score $(\mathrm{AOR}=4.366, \mathrm{p}=0.000)$. However, being highly educated and working were non-significant independent factors (AOR=1.894 and 1.636, $\mathrm{p}>0.05$ ) (Table 5). Most common sources of mothers' information about children obligatory vaccination were from health centers $(71.0 \%)$ and their relatives $(67.0 \%)$ and the least one was from heath card $(3.0 \%)$ (Figure 1)

Most common barriers of none or partial vaccination among studied sample were a sick child (63.0\%) followed by family problems $(31.0 \%)$ and the least reason was fear of vaccination side effect $(11.0 \%)$ (Figure 2)

\section{Discussion}

Child vaccination has a major role in the preventive aspects of infectious diseases like morbidities, disability, and death. Giving the child the appropriate vaccinations would significantly decrease the costs of disease treatment and rates of disease occurrence thus achieving a good quality of life for children. ${ }^{12}$

The study revealed a high percentage of inadequate total knowledge score among the studied mothers $(61 \%)$ and about half of them had a poor practice of $(59 \%)$ towards obligatory vaccines. This was in contrast with a study done in Saudi Arabia, 2018 which revealed a total high KAP (knowledge, attitude, and practice) of the studied parents (87.2\%). ${ }^{12}$ Also, a retrospective record based study done in Catalonia revealed that about $70 \%$ of the studied parents thought that vaccination should be obligatory and of great importance in the babies' life. ${ }^{13}$ An Iraqi study, 2014 showed $66.1 \%$ of the parents were found to have adequate KP scores regarding children vaccination. ${ }^{6}$ 
Multivariate regression revealed that mothers' age (above 30 years), highly educated, working, and of high social class were independent predictors for adequate total knowledge score, this can be explained with increasing the mothers' experience by time and high contact with the community and gaining more informative data. As regarding practice score - on the opposite - multivariate analysis revealed that mothers of high social class was the only significant independent variable for good practice score this may be explained by higher awareness and better environmental conditions, These results were supported by a study done in Japan which found that children whose mothers were younger and less educated, and those of low socioeconomic standard were at a high risk of not being up-to-date with the immunization status with significant negative practice. ${ }^{14}$ An Indian study, 2017 done on 500 mothers proved that high mothers' awareness and complete child vaccination were associated with mothers age (> 26 years) and higher education. ${ }^{15}$

A study done at Al-Beida City, Libya showed reversed results which demonstrated that mothers' education and occupation didn't affect child vaccination. ${ }^{16}$ The same was demonstrated by Saudi study done on 420 Saudi parents in Hail City, which showed no statistical significance between the higher KAP and age or education level. ${ }^{17}$ Different results were showed by a cohort study done in two northern Italian regions as follows; mothers who were over 35 or less than 25 years old, with higher formal education, and citizens of highly-developed countries were less compliant with vaccination recommendations with evident negative attitude in both the regions. ${ }^{18}$
The commonest source of mothers' information was health care providers (doctors and paramedics) in the primary health centers $(71 \%)$ this was expected as they are the vaccination service providers, then the family relatives $(67 \%)$, television (TV) and social media (53\% and 34\% respectively), and the least one was birth health card (the blue one for a boy baby and the pink one for a girl baby). There was an obvious relationship between vaccine confidence and confidence in the child's physician whereas mothers that were confident in the health care providers were more likely to be confident in vaccines and greatly encouraged to complete the child vaccinations. ${ }^{19}$ Similar results reported by a study done in Solvania and found that physicians $(84.6 \%)$ and friends $(51.9 \%)$ were the commonest sources of mothers' information regarding child vaccines. ${ }^{19} \mathrm{~A}$ cross-sectional study done in Poland revealed that parents who take their information from medical professionals showed proper practice and adherence to vaccination schedules and mothers who used less informative professional sources (e.g. leaflets, social media) and those with a lower level of education were more likely to avoid vaccination. ${ }^{20}$ Another study done in Egypt on 385 mothers attending Al-Amyria Family Centre asking about their sources of information regarding obligatory vaccines revealed that the health care provider was the main source $(32.5 \%)$ followed by TV $(26.5 \%)$ regardless mothers' age or level of education. $^{21}$

The current study revealed that sick baby (chronically ill baby with a permanent illness with longevity as hepatic or renal affection) / or long term baby illness which is acute disease takes long management course but treatable and curable) was the 
commonest barrier for none or incomplete child vaccination (63\%) due to the mother's concept of her baby can't tolerate the vaccination side effects because of his illness, followed by the presence of family problems $(31 \%)$ (Divorce, neglect, and death of mother or father) due to the family preoccupation or neglect, lack of knowledge and fear of vaccination side effects were the least ones $(28 \%$ and $11 \%$ respectively). A study done in the United States showed that fear of vaccination side effects (as autism), Objection to a large number of injections, lack of access, and lack of information were the commonest causes of non and partial child immunization which recommended to be overcome. $^{22}$ These were in concomitant with a study done in Ethiopia, 2018 among 484 mothers showed that the most common reasons for non or incomplete child vaccination were fear of adverse reactions $(36 \%)$, being too busy $(31 \%)$, or hearing hearsays about vaccines $(28 \%){ }^{23} \mathrm{~A}$ systematic review for many published in peer-reviewed journals in English, Spanish and Portuguese languages from January 1992 to June 2014 was implemented and reported that the most cited factors affecting mothers adherence to vaccination schedule were higher birth order, low maternal education/ socioeconomic status and irregular follow up by health care services (documenting the next vaccination session date or calling upon delay). ${ }^{24}$

\section{Conclusion}

Mother's knowledge and practice regarding children's obligatory vaccination is unsatisfactory. The health care providers and media played an important role in providing the public with trustful information.

\section{Recommendation}

Continuous health education sessions should be provided in all primary health care facilities with the help of TV programs and other media facilities to enhance public adherence to the vaccination schedule.

Study limitations: the study site should be expanded to include samples from the other health districts, and applied on larger sample size.

Acknowledgment: we would like to express great thanking to all participants and all health facilities' staff for their help to accomplish this work.

\section{References}

1. Yousif M, Albarraq A, Abdallah M, Elbur A. Parents' knowledge and attitudes on childhood immunization, Taif, Saudi Arabia. J Vaccines Vaccin. 2013 Dec;5(215):2.

2. Birhanu S, Anteneh A, Kibie Y, Jejaw A. Knowledge, attitude and practice of mothers towards immunization of infants in health Centres at Addis Ababa, Ethiopia. Am J Health Res. 2016 Feb 16;4(1):6-17.

3. Siddiqi N, Siddiqi AA, Nisar N, Khan A. Mothers' knowledge about EPI and its relation with age-appropriate vaccination of infants in peri-urban Karachi. JPMA-Journal of the Pakistan Medical Association. 2010 Nov 1;60(11):940.

4. World Health Organization. Causality assessment of an adverse event following immunization (AEFI): user manual for the revised WHO classification, 2018.

5. World Health Organization. "WHO vaccine-preventable diseases: monitoring system. 2019 global summary. Geneva, Switzerland: World Health Organization; 2019." 25-44.

6. Al-Lela OQ, Bahari MB, Al-Qazaz HK, Salih MR, Jamshed SQ, Elkalmi RM. Are parents' knowledge and practice regarding immunization related to pediatrics' immunization compliance? a mixed method study. BMC pediatrics. 2014 Dec;14(1):20.

7. Mugada V, Chandrabhotla S, Kaja DS, Machara SG. Knowledge towards childhood 
immunization among mothers \& reasons for incomplete immunization. J Appl Pharm Sci. 2017 Oct;7(10):157-61.

8. Braczkowska B, Kowalska M, Braczkowski R, Barański K. Determinants of vaccine hesitancy. Prz. Epidemiol. 2017;71:227-36.

9. Ramadan HA, Soliman SM, El-kader RG. Knowledge, attitude and practice of mothers toward children's obligatory vaccination. Journal of Nursing and Health Science. 2016;5(4):22-8.

10. Fahmy SI, Nofal LM, Shehata SF, El Kady $\mathrm{HM}$, Ibrahim HK. Updating indicators for scaling the socioeconomic level of families for health research. J Egypt Public Health Assoc. 2015 Mar 1;90(1):1-7.

11. Taukobong NP, Myezwa H, Pengpid S, Van Geertruyden JP. Knowledge, attitude and practice about health promotion amongst physiotherapists in South Africa. Physiotherapy. 2015 May 1;101:e1491-2.

12. Saleh A, Alrashidi AA, Bukhari MA, Habib RF, Alsubhi RA, Saadawi DW, Hatim RF. Assessment of knowledge, attitude and practice of parents towards immunization of children in Saudi Arabia, 2018. Egypt J Hosp Med. 2018 Apr 1;71(2):2585-9.

13. Borràs E, Domínguez À, Fuentes M, Batalla J, Cardeñosa N, Plasencia A. Parental knowledge of paediatric vaccination. BMC Public Health. 2009 Dec;9(1):154.

14. Ueda M, Kondo N, Takada M, Hashimoto H. Maternal work conditions, socioeconomic and educational status, and vaccination of children: a community-based household survey in Japan. Preventive medicine. 2014 Sep 1;66:17-21.

15. Dharmalingam A, Raghupathy NS, Sowmiya M, Amudharaj D, Jehangir HM. Immunization knowledge, attitude and practice among mothers of children from 0 to 5 years. Int J Contemp Pediatrics. 2017 May;4(3):783.

16. Bofarraj MA. Knowledge, attitude and practices of mothers regarding immunization of infants and preschool children at Al-Beida City, Libya 2008. Egyptian Journal of
Pediatric Allergy and Immunology (The). 2011;9(1).

17. Alshammari TM, Alsubaie YS, Ali S, Alajmi NM, Alanazi KK, Alamir MA, Albenawi ZA, Alsahli AM, Alsharkhat NS, Almejlad AJ, Almatrafi MN. Assessment of Knowledge, Attitude and Practice of Parents about Immunization in Hail City, 2018. Egypt J Hosp Med. 2018 Oct 1;73(3):6377-81.

18. Anello P, Cestari L, Baldovin T, Simonato L, Frasca G, Caranci N, Pascucci MG, Valent F, Canova C. Socioeconomic factors influencing childhood vaccination in two northern Italian regions. Vaccine. 2017 Aug 24;35(36):4673-80.

19. Učakar V, Fafangel M, Kraigher A. Vaccine confidence among mothers of young children, Slovenia, 2016. Vaccine. 2018 Sep 5;36(37):5544-50.

20. Kowalska M, Gajda M, Barański K, Braczkowska B. Sources of parental knowledge about the safety of vaccinations in Poland. Health promotion international. 2019 Dec 1;34(6):1191-9.

21. El Awady MY, El Ezz NF, Momen MT, Metwaly MM. Knowledge of Mothers about Side Effects of Obligatory Vaccines in Alamyria Family Medicine Center, Cairo. Egyptian Journal of Community Medicine. 2016 Apr;34(2).

22. Ventola CL. Immunization in the United States: recommendations, barriers, and measures to improve compliance: part 1: childhood vaccinations. Pharmacy and Therapeutics. $2016 \mathrm{Jul}$;41(7):426.

23. Tefera YA, Wagner AL, Mekonen EB, Carlson BF, Boulton ML. Predictors and barriers to full vaccination among children in Ethiopia. Vaccines. 2018 Jun;6(2):22.

24. de Cantuária Tauil M, Sato AP, Waldman EA. Factors associated with incomplete or delayed vaccination across countries: a systematic review. Vaccine. 2016 May 23;34(24):2635-43. 